\title{
Casca de Algodão em Substituição Parcial à Silagem de Capim-Elefante para Novilhos. 1. Consumo, Degradabilidade e Digestibilidade Total e Parcial ${ }^{1}$
}

\author{
Mario Luiz Chizzotti ${ }^{2}$, Sebastião de Campos Valadares Filho ${ }^{3}$, Maria Ignês Leão ${ }^{3}$, Rilene \\ Ferreira Diniz Valadares ${ }^{4}$, Fernanda Helena Martins Chizzotti ${ }^{5}$, Karla Alves Magalhães ${ }^{5}$, \\ Marcos Inácio Marcondes 6
}

\begin{abstract}
RESUMO - Quatro novilhos holandeses fistulados no rúmen, com peso médio de $259 \mathrm{~kg}$, foram distribuídos em um quadrado latino 4 x 4 para se avaliar o efeito dos níveis de casca de algodão na dieta de novilhos sobre o consumo e as digestibilidades totais, ruminais e intestinais de matéria seca (MS), matéria orgânica (MO), extrato etéreo (EE), proteína bruta (PB), fibra em detergente neutro corrigida para cinzas e proteína (FDNcp) e carboidratos não-fibrosos corrigidos (CNFcp) e o consumo de nutrientes digestíveis totais (NDT). Também foi avaliada a cinética de degradação ruminal da casca de algodão, da silagem de capim-elefante, do sorgo e do farelo de soja. As dietas experimentais continham na base da matéria seca: 0, 10,20 e 30\% de casca de algodão peletizada, em substituição à silagem de capimelefante, sendo a dieta total constituída de $60 \%$ de volumoso. As digestibilidades foram determinadas utilizando-se a fibra em detergente ácido indigestível como indicador. No ensaio de degradabilidade, foram utilizados dois novilhos e os tempos de incubação ruminal 0,3 , $6,12,24,48,72,96$ e 144 horas. Verificou-se que os níveis de casca de algodão aumentaram linearmente o consumo diário de todos os nutrientes, tanto em $\mathrm{kg}$ quanto em \% do peso vivo. Não houve efeito dos diferentes tratamentos sobre as digestibilidades totais e parciais dos nutrientes e, conseqüentemente, não houve efeito sobre o teor de NDT das dietas, que foi em média 59,53\%. O NDT calculado da casca de algodão foi de 55,52\%. A degradação efetiva da MS, para a taxa de passagem estimada de 5,06\%/h, foi de 38,65; 41,13; 68,58 e 77,56\% para a casca de algodão, a silagem de capim-elefante, o sorgo e o farelo de soja, respectivamente. A casca de algodão mostrouse um bom volumoso alternativo, podendo ser fornecida até o nível de 30\% na MS total na dieta de novilhos de origem leiteira.
\end{abstract}

Palavras-chave: digestibilidade intestinal, digestibilidade ruminal, Holandês, subproduto, volumoso

\section{Partial Replacement of Elephantgrass Silage with Cottonseed Hulls. 1. Intake, Degradability, and Apparent Ruminal, Intestinal, and Total Tract Digestibilities in Steers}

ABSTRACT - Four ruminally cannulated Holstein steers averaging $259 \mathrm{~kg}$ of body weight were randomly assigned to a $4 \mathrm{x} 4 \mathrm{Latin}$ square to study the effects of replacing elephantgrass silage with cottonseed hulls on intake and apparent ruminal, intestinal, and total tract digestibilities of dry matter (DM), organic matter (OM), ether extract (EE), crude protein (CP), neutral detergent fiber corrected to ash and protein (NDFap), and corrected non-fiber carbohydrates (NFCap). Intake of total digestible nutrients (TDN) and ruminal degradabilities of cottonseed hulls, elephantgrass silage, sorghum, and soybean meal also were evaluated. Treatments (60\% of forage) contained on DM basis: $0,10,20$ or $30 \%$ of cottonseed hulls that partially replaced elephantgrass silage in the diet. Digestibilities were obtained using indigestible acid detergent fiber as an internal marker. To determine ruminal degradability of the feeds two steers were used and the following incubation times were adopted: zero, three, six, 12, 24, 48, 72, 96 and 144 hours. Daily intake of all nutrients expressed either as an amount or as percentage of body weight, increased linearly by partially replacing elephantgrass silage with cottonseed hulls. No effects of increasing levels of cottonseed hulls were observed for apparent ruminal, intestinal, and total tract digestibilities of nutrients in the current trial. Consequently, contents of dietary TDN did not differ and averaged 59.53\% across diets. In addition, calculated TDN was $55.52 \%$ for cottonseed hulls. Effective DM degradation, assuming a passage rate of 5.06\%/h, was $38.65 ; 41.13 ; 68.58$, and $77.56 \%$ for cottonseed hulls, elephantgrass silage, sorghum, and soybean meal, respectively. It can be concluded that cottonseed hulls is a good forage alternative to elephantgrass silage and may supply up to $30 \%$ of the total DM in diets of dairy steers.

Key Words: by-product, Holstein, intestinal digestibility, roughage, ruminal digestibility

\footnotetext{
${ }_{1}$ Parte da tese de Mestrado do primeiro autor, parcialmente financiado pela Bünge Alimentos S.A

2 Zootecnista, MS, Doutorando em Zootecnia - UFV (mariochizzotti@bol.com.br).

${ }^{3}$ Professor Titular do Departamento de Zootecnia - UFV (scvfilho@ufv.br; mileao@ufv.br).

${ }^{4}$ Professora Adjunto do Departamento de Medicina Veterinária - UFV (rilene@ufv.br).

5 Doutoranda em Zootecnia - UFV.

6 Mestrando em Zootecnia - UFV.
} 


\section{Introdução}

O baixo rendimento zootécnico da pecuária de corte, em muitos sistemas de exploração, tem sido expressivamente alterado pela intensificação da produção e pela utilização do confinamento como estratégia gerencial e alimentar. A alimentação de bovinos confinados representa a maior parte dos custos operacionais, sendo o alimento volumoso o ingrediente, individualmente, de menor custo na dieta, o que torna atraente a maximização da sua utilização, respeitando-se a relação entre a diminuição no custo:redução no desempenho, de forma a otimizar a margem de lucro (Valadares Filho et al., 2002a). Na escolha do volumoso, devem-se considerar seu preço, sua facilidade operacional e a infra-estrutura necessária à sua utilização.

A casca de algodão compreende a camada externa do caroço de algodão com algum línter aderido, separada durante o beneficiamento visando à produção de óleo. Este subproduto apresenta alto teor de fibra, o que o torna pouco atraente na alimentação de monogástricos e interessante como alimento volumoso alternativo para ruminantes.

Alimentos ricos em fibra e pouco digestíveis geralmente reduzem o consumo de MS, como conseqüência da quantidade de material indigestível, que ocupa espaço dentro do rúmen, causando distensão física do epitélio ruminal (Church, 1993). Apesar do elevado teor de FDN e FDA da casca de algodão, este subproduto tem a característica peculiar de não afetar o consumo. Ao contrário, diversos autores relataram aumento linear do consumo por bovinos de corte (Moore et al., 1990; Bartle et al., 1994; Magalhães et al., 2003) e de leite (Harris et al., 1983; Van Horn et al., 1984; Morales et al., 1989; Adams et al., 1995; Gu et al., 1996; Gu \& Moss, 1996; citados por Hall \& Akinyode, 2000) alimentados com este subproduto.

Além do conhecimento da composição bromatológica e da ingestão de alimentos, é importante o conhecimento da utilização dos nutrientes pelo animal, que é obtido por meio de estudos de digestão e de degradabilidade ruminal. O conhecimento dos locais de digestão dos nutrientes é importante, pois permite calcular as quantidades aparentemente absorvidas nos diferentes segmentos do trato digestivo. A literatura internacional reporta que a casca de caroço de algodão diminui a digestibilidade da dieta (Moore et al.,1990; Bartle et al., 1994; Akinyode et al., 1999). A digestibilidade da casca de algodão é provavelmente afetada pela sua forma física e também pelo teor de nutrientes (Hall \& Akinyode, 2000).

A eficiência da extração da pluma e da retirada da casca de algodão não é constante. Logo, a casca de algodão pode conter diferentes proporções entre línter e polpa, implicando em composição bromatológica variável. A variabilidade na composição resulta em diferentes respostas de desempenho animal. A literatura nacional é carente de informações a respeito do emprego da casca de algodão produzida no país e, portanto, não há recomendação do nível de utilização deste alimento.

Este trabalho foi realizado objetivando-se avaliar, em novilhos de origem leiteira, o efeito da inclusão da casca de algodão na dieta em substituição parcial à silagem de capim-elefante sobre o consumo e as digestibilidades totais, ruminais e intestinais dos nutrientes. Também foi avaliada a cinética de degradação ruminal dos alimentos utilizados.

\section{Material e Métodos}

O experimento foi conduzido no Laboratório de Animais e no Laboratório de Nutrição Animal do Departamento de Zootecnia da Universidade Federal de Viçosa, em Viçosa, MG, sendo a fase de campo realizada entre julho e setembro de 2002. A cidade de Viçosa está localizada na Zona da Mata de Minas Gerais e tem como coordenadas geográficas $20^{\circ} 45^{\prime} 20^{\prime \prime}$ de latitude sul e $45^{\circ} 52^{\prime} 40^{\prime \prime}$ de longitude oeste de Greenwich e altitude de $657 \mathrm{~m}$. A temperatura média e a precipitação pluviométrica observadas nos anos de 2000 e 2001 foram, respectivamente, de $20^{\circ} \mathrm{C}$ e $1217,9 \mathrm{~mm}$ e $20,7^{\circ} \mathrm{C}$ e $1148 \mathrm{~mm}$ (UFV, 2002).

Foram utilizados quatro novilhos não-castrados, com grau de sangue predominantemente Holandês, fistulados no rúmen, segundo as técnicas descritas por Leão \& Coelho da Silva (1980). Os animais foram pesados no início e no final de cada período experimental. O peso médio dos novilhos durante o experimento foi de $259 \mathrm{~kg}$. Os animais foram mantidos em regime de confinamento, alojados em baias individuais cobertas, com piso de concreto revestido de borracha, de $9 \mathrm{~m}^{2}$ de área $(3 \times 3 \mathrm{~m})$, dotadas de comedouros e bebedouros individuais.

O delineamento experimental utilizado foi o quadrado latino 4 x 4, sendo quatro animais, quatro períodos experimentais e quatro tratamentos.

A alimentação foi fornecida uma vez ao dia, na forma de ração completa, à vontade, permitindo so- 
bras de no máximo 5\%, sempre às $7 \mathrm{~h}$. Os quatro tratamentos consistiram de dietas com níveis crescentes de casca de algodão peletizada como volumoso $(0,10,20$ e $30 \%)$ em substituição parcial (na base da matéria seca total) à silagem de capim-elefante, sendo a dieta total constituída de $60 \%$ de volumoso, na base seca. As dietas foram balanceadas de acordo com o NRC (1996), para conterem em torno de $13 \%$ de PB.

A proporção dos ingredientes nas dietas experimentais encontra-se na Tabela 1; a composição químico-bromatológica dos ingredientes, na Tabela 2; e a composição média das dietas experimentais, na Tabela 3.

Tabela 1 - Proporção dos ingredientes nas dietas experimentais, na base da matéria seca Table 1 - Ingredient composition (\%) of the experimental diets on dry matter basis

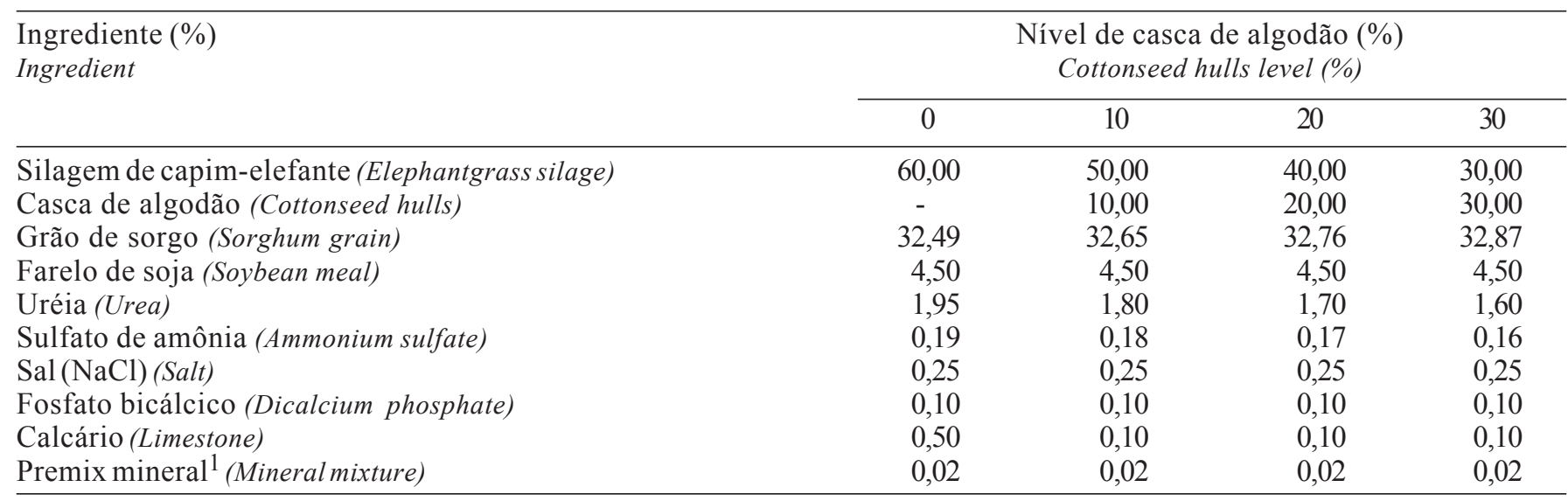

${ }^{1}$ Composição: sulfato de cobalto, 1,82\%; sulfato de cobre, 22,69\%; iodato de potássio, 0,45\%; selenito de sódio, 0,09\%; sulfato de zinco, $74,95 \%$.

${ }^{1}$ Composition: cobalt sulfate, $1.82 \%$; cupric sulfate, $22.69 \%$; potassium iodide, $0.45 \%$; sodium selenate, $0,09 \%$; zinc sulfate, $74.95 \%$.

Tabela 2 - Teores de matéria seca (MS), matéria orgânica (MO), proteína bruta (PB), nitrogênio insolúvel em detergente neutro (NIDN), nitrogênio insolúvel em detergente ácido (NIDA), extrato etéreo (EE), fibra em detergente neutro corrigida para cinzas e proteína (FDNcp), fibra em detergente neutro (FDN), carboidratos não-fibrosos corrigidos (CNFcp), carboidratos não-fibrosos (CNF), fibra em detergente ácido (FDA), lignina e fibra em detergente ácido indigestível (FDAi) dos ingredientes utilizados nas dietas experimentais

Table 2 - Contents of dry matter (DM), organic matter (OM), crude protein (CP), neutral detergent insoluble nitrogen (NDIN), acid detergent insoluble nitrogen (ADIN), ether extract (EE), neutral detergent fiber corrected to ash and protein (NDFap), neutral detergent fiber (NDF), corrected nonfiber carbohydrates (NFCap), nonfiber carbohydrates (NFC), acid detergent fiber (ADF), lignin and indigestible acid detergent fiber (iADF) of ingredients of the experimental diets

\begin{tabular}{|c|c|c|c|c|}
\hline \multirow{2}{*}{$\begin{array}{l}\text { Item } \\
\text { Item }\end{array}$} & \multicolumn{4}{|c|}{$\begin{array}{l}\text { Ingrediente } \\
\text { Ingredient }\end{array}$} \\
\hline & $\begin{array}{l}\text { Silagem de capim-elefante } \\
\text { Elephantgrass silage }\end{array}$ & $\begin{array}{l}\text { Casca de algodão } \\
\text { Cottonseed hulls }\end{array}$ & $\begin{array}{l}\text { Grão de sorgo } \\
\text { Sorghum grain }\end{array}$ & $\begin{array}{c}\text { Farelo de soja } \\
\text { Soybean meal }\end{array}$ \\
\hline$\overline{M S}(\%)(D M)$ & 25,64 & 87,40 & 88,72 & 90,64 \\
\hline $\mathrm{MO}^{1}(O M)$ & 90,98 & 97,16 & 98,29 & 93,13 \\
\hline $\mathrm{PB}^{1}(C P)$ & 4,32 & 8,08 & 9,88 & 45,10 \\
\hline $\mathrm{NIDN}^{2}$ (NDIN) & 29,82 & 19,99 & $26,79^{3}$ & $5,75^{3}$ \\
\hline $\mathrm{NIDA}^{2}(A D I N)$ & 21,60 & 9,73 & $23,66^{3}$ & $2,77^{3}$ \\
\hline $\mathrm{EE}^{1}$ & 1,65 & 2,93 & 4,05 & 2,29 \\
\hline $\mathrm{FDNcp}^{1}$ (NDFap) & 74,07 & 74,78 & 8,68 & 13,76 \\
\hline $\mathrm{FDN}^{1}(N D F)$ & 77,68 & 78,99 & 9,94 & 15,08 \\
\hline $\mathrm{CNFcp}^{1}$ (NFCap) & 10,94 & 11,37 & 75,68 & 31,98 \\
\hline $\mathrm{CNF}^{1}(N F C)$ & 14,55 & 15,58 & 76,94 & 33,30 \\
\hline $\mathrm{FDA}^{1}(A D F)$ & 52,01 & 61,70 & 5,95 & 13,27 \\
\hline Lignina $^{1}$ (Lignin) & 10,53 & 11,54 & 1,81 & 2,52 \\
\hline $\mathrm{FDAi}^{1}(i A D F)$ & 29,78 & 30,98 & 1,05 & 0,66 \\
\hline
\end{tabular}

$1 \%$ MS; $2 \%$ do $\mathrm{N}$ total; ${ }^{3}$ Valadares Filho et al. (2002b).

$1 \%$ DM; $2 \%$ of total $N{ }^{3}$ Valadares Filho et al. (2002b). 
Diariamente, foram registradas as quantidades de de alimento fornecidas e as sobras, de cada animal, para estimativa do consumo. No momento da alimentação, durante o período experimental, foram realizadas amostragens dos alimentos e das sobras, que foram acondicionados em sacos plásticos e congelados para análises posteriores. Os períodos experimentais tiveram duração de 13 dias, sendo seis dias de adaptação às dietas. As coletas de fezes e da digesta de omaso foram realizadas em intervalos de 52 horas, às $8 \mathrm{~h}$ do dia 1 , às $12 \mathrm{~h}$ do dia 3 e às $16 \mathrm{~h}$ do dia $5 \mathrm{dos}$ períodos de coleta. A coleta de digesta omasal foi realizada por sucção do conteúdo omasal, segundo técnica descrita por Leão et al. (2002). As amostras de fezes e de digesta omasal foram pré-secas em estufa de ventilação forçada, a $65^{\circ} \mathrm{C}$ por 72 horas, processadas em moinho de facas com peneira de crivos de $1 \mathrm{~mm}$, sendo elaborada uma amostra composta por animal por período, com base no peso seco de cada subamostra.

Foi realizado um ensaio de degradabilidade durante o período de adaptação do último período experimental. Foram utilizados sacos de náilon medindo 10 x $20 \mathrm{~cm}$, com porosidade de $50 \mu$, onde se adicio-

Tabela 3 - Teores de matéria seca (MS), matéria orgânica (MO), proteína bruta (PB), extrato etéreo (EE), fibra em detergente neutro corrigida para cinzas e proteína (FDNcp), carboidratos nãofibrosos corrigidos (CNFcp) e lignina, das dietas experimentais, em \% da matéria seca

Table 3 - Contents of dry matter (DM), organic matter (OM), crude protein $(C P)$, ether extract $(E E)$, neutral detergent fiber corrected to ash and protein (NDFap), corrected nonfiber carbohydrates (NFCap) and lignin of the experimental diets on dry matter basis

\begin{tabular}{lcccc}
\hline \multirow{2}{*}{$\begin{array}{l}\text { Item } \\
\text { Item }\end{array}$} & \multicolumn{4}{c}{ Nível de casca de algodão (\%) } \\
& \multicolumn{1}{c}{0} & \multicolumn{1}{c}{10} & \multicolumn{1}{c}{20} & \multicolumn{1}{c}{30} \\
\cline { 2 - 5 } MS (\%) & 49,65 & 55,72 & 61,89 & 68,26 \\
DM (\%) & & & & \\
MO & 93,04 & 93,82 & 94,37 & 94,99 \\
OM & 13,27 & 13,24 & 13,35 & 13,46 \\
PB & 2,41 & 2,55 & 2,68 & 2,81 \\
CP & 47,88 & 47,97 & 48,05 & 48,13 \\
EE & & & & \\
FDNcp & 29,48 & 30,06 & 30,29 & 30,59 \\
NDFap & & & & \\
CNFcp & 7,02 & 7,12 & 7,23 & 7,33 \\
NFCap & & & & \\
Lignina & & & & \\
Lignin & &
\end{tabular}

naram $5 \mathrm{~g}$ de amostras de casca de algodão peletizada, silagem de capim-elefante, sorgo ou farelo de soja, secas em estufa a $60^{\circ} \mathrm{C}$ e moídas, utilizando-se peneira com crivos de $2 \mathrm{~mm}$. Os tempos de incubação utilizados foram $0,3,6,12,24,48,72,96$ e 144 horas. Os alimentos foram incubados em dois animais dos tratamentos com 10 e $20 \%$ de casca de algodão na dieta, por intermédio da fístula ruminal, fixados a uma corrente de aço com peso na extremidade, para a imersão das amostras no conteúdo ruminal. Decorrido o tempo de incubação, os sacos foram lavados em água e levados à estufa a $65^{\circ} \mathrm{C}$, por 72 horas, sendo posteriormente determinados os teores de MS, PB e FDN dos resíduos da incubação, conforme Silva \& Queiroz (2002). A degradabilidade da MS e PB foi calculada pelo modelo de crescimento assintótico de primeira ordem, reparametrizado por Orskov \& McDonald (1979), descrito pela função: $Y=a+b *(1-$ $\mathrm{e}^{\left(-\mathrm{Kd}^{*} \mathrm{t}\right)}$, em que $\mathrm{Y}$ é o desaparecimento de cada nutriente; a, a fração solúvel; b, a fração insolúvel, mas potencialmente degradável; $\mathrm{Kd}$, a taxa de degradação de b; e t, a variável independente tempo. A degradação efetiva (DE) da PB e da MS foi calculada pelo modelo: $\mathrm{DE}=\mathrm{a}+\mathrm{b}^{*} \mathrm{Kd} /(\mathrm{Kd}+\mathrm{kp})$, em que kp é a taxa de passagem do alimento pelo rúmen, estimada pelas equações propostas pelo NRC (2001).

Para a degradabilidade da FDN, utilizou-se o modelo exponencial decrescente proposto por Mertens \& Loften (1980): $\mathrm{Y}=\mathrm{b}+\mathrm{i}$, para $0<\mathrm{t}<\mathrm{L}$ e $\mathrm{Y}=\mathrm{b}^{*} \mathrm{e}^{(-}$ $\left.\mathrm{Kd}^{*}(\mathrm{t}-\mathrm{L})\right)+\mathrm{i}$, para $\mathrm{t}>\mathrm{L}$. Em que $\mathrm{Y}$ é o resíduo de incubação; i, a fração indigestível; e L, o período de latência. A DE da FDN foi calculada por: $\mathrm{DE}=$ $\mathrm{b} * \mathrm{Kd} * \mathrm{e}^{-\mathrm{k} * \mathrm{~L} /(\mathrm{Kd}+\mathrm{kp})}$.

Nas amostras de alimentos, sobras, fezes e de conteúdo omasal, foram determinados os teores MS, MO, nitrogênio total e EE e, nas amostras de alimentos, os teores de fibra em detergente ácido (FDA), nitrogênio insolúvel em detergente ácido (NIDA) e nitrogênio insolúvel em detergente neutro (NIDN), conforme Silva \& Queiroz (2002). A FDN foi determinada pela técnica da autoclave, segundo Rennó et al. (2002), sendo quantificados os teores de PB e de cinzas da FDN, conforme Silva \& Queiroz (2002), para determinação da FDN corrigida (FDNcp). Foram considerados os teores de NIDN e NIDA do grão de sorgo e do farelo de soja descritos por Valadares Filho et al. (2002b).

A fibra em detergente ácido indigestível (FDAi) foi utilizada como indicador interno, sendo determinada 
nas amostras de alimentos, fezes, digesta omasal e sobras, por meio da incubação ruminal durante 144 horas de $0,5 \mathrm{~g}$ de amostra em sacos Ankom (filter bags F57), que, posteriormente, foram lavados em água, fervidos em detergente ácido por 1 hora, lavados em água destilada e em acetona e secos em estufa a $65^{\circ} \mathrm{C}$, por 72 horas, conforme proposto por Cochran et al. (1986).

Em virtude da presença de uréia nos concentrados, os CNF foram calculados como proposto por Hall $(2000): \mathrm{CNF}=100-[(\% \mathrm{~PB}-\% \mathrm{~PB}$ derivada da uréia $+\%$ de uréia) $+\%$ FDNcp $+\%$ EE $+\%$ cinzas $]$.

Os nutrientes digestíveis totais (NDT) foram calculados por: $\mathrm{NDT}=\% \mathrm{PBdigestível}+\% \mathrm{FDNdigestível}$ $+\%$ CNFdigestível $+(2,25 * \%$ EEdigestível $)$. O NDT da casca de algodão foi estimado por meio de sistema de equações envolvendo os tratamentos com 20 e $30 \%$ de casca.

Os dados foram avaliados por meio de análises de variância e regressão do tipo polinomial. Todas as análises estatísticas foram realizadas utilizando-se o Sistema de Análises Estatísticas e Genéticas - SAEG (UFV, 1998). Os coeficientes de variação apresentados são relativos aos dados.

\section{Resultados e Discussão}

Constam na Tabela 4 os consumos médios dos nutrientes, em kg/dia e em porcentagem do peso vivo/ dia, as respectivas equações de regressão e os coeficientes de variação e de determinação, para os diferentes tratamentos. Verificou-se que a inclusão de casca de algodão na dieta aumentou linearmente o consumo diário de praticamente todos os nutrientes, tanto em $\mathrm{kg}$ quanto em $\%$ do peso vivo. O consumo de matéria seca é de fundamental importância, pois determina o nível de ingestão de nutrientes pelo animal e estabelece a quantidade de nutrientes disponíveis para mantença e produção. Alimentos volumosos, reconhecidamente de baixa digestibilidade, podem reduzir o consumo de MS, pois, em razão de sua baixa taxa de degradação, seu lento desaparecimento do rúmen e passagem pelo trato gastrintestinal, podem causar o enchimento ruminal. Segundo Allen (1996), o epitélio do retículo-rúmen possui receptores de tensão e táteis que afetam negativamente o consumo quando estimulados, como no caso da distensão ruminal, em decorrência do acúmulo de digesta.

Embora geralmente o teor de FDN esteja correlacionado negativamente ao consumo de MS, diversos autores relataram aumento no consumo de dietas contendo casca de algodão (Moore et al., 1990; Bartle et al., 1994; Hall \& Akinyode, 2000), indicando que a casca de algodão não tem o mesmo efeito depressivo no consumo que outros volumosos. Morales et al. (1989) encontraram decréscimo no consumo de MS em porcentagem do peso vivo com o aumento do teor de FDN da ração pela adição de pré-secado de alfafa à dieta. Entretanto, verificaram aumento no consumo de matéria seca ao elevar o teor de FDN ao mesmo nível utilizando a casca de algodão. De acordo com o NRC (2001), a estimativa do consumo de matéria seca a partir do teor de FDN dietético não é muito acurada, existindo influência do tamanho da partícula, digestibilidade e taxa de passagem da fonte de FDN que determinam variações no consumo. Moore et al. (1990), substituindo metade do feno de alfafa por casca de algodão ou palhada de trigo para novilhos alimentados com dietas contendo $35 \%$ de volumoso, relataram aumento no consumo dos animais recebendo casca de algodão em relação àqueles consumindo somente feno de alfafa como volumoso ( $6,9 \mathrm{vs} 5,9 \mathrm{~kg} / \mathrm{dia})$ e que, durante o esvaziamento do rúmen, observou-se que a digesta ruminal dos animais que consumiram casca de algodão apresentou-se homogênea e menos estratificada que a digesta dos animais dos demais tratamentos. Segundo os autores, isto deve ter influenciado o aumento da taxa de passagem do conteúdo ruminal, e, como o consumo e a taxa de passagem são positivamente relacionados, a passagem mais rápida permitiu aos animais aumentarem o consumo de matéria seca. O tamanho da partícula também influencia a taxa de escape ruminal, e notadamente as partículas de casca de algodão eram inferiores às partículas da silagem de capimelefante utilizadas neste experimento.

Estudando os mesmos níveis de substituição de silagem de capim-elefante por casca de algodão em dietas contendo $60 \%$ de volumoso, Magalhães et al. (2003) observaram aumentos lineares nos consumos de MS e FDN, expressos em relação ao peso vivo. Entretanto não observaram diferenças significativas para os consumos de PB, CNF e NDT. Avaliando diferentes volumosos para bovinos em terminação, Defoor et al. (2002) encontraram maiores consumos $(\mathrm{P}<0,10)$ de energia líquida para ganho em relação ao peso metabólico pelos animais que consumiram casca de algodão do que os que consumiram feno de alfafa. De acordo com Hall \& Akinyode (2000), os dados 
Tabela 4 - Médias, equações de regressão (equações), coeficientes de variação (CV) e determinação ( $\left.R^{2}\right)$, obtidos para os consumos de matéria seca (MS), matéria orgânica (MO), proteína bruta (PB), extrato etéreo (EE), fibra em detergente neutro corrigida (FDNcp), carboidratos não-fibrosos corrigidos (CNFcp), nutrientes digestíveis totais (NDT), MO degradada no rúmen (MOdr) e carboidratos degradados no rúmen (CHOdr), em função dos níveis de casca de algodão (CA) nas rações

Table 4 - Means, regression equation (equations), coefficients of variation and determination (CV and $R^{2}$ ) of intakes of dry matter $(D M)$, organic matter (OM), crude protein (CP), ether extract (EE), neutral detergent fiber corrected (NDFap), corrected nonfiber carbohydrates (NFCap), total digestible nutrients (TDN), ruminally degraded organic matter (RDOM), and ruminally degraded carbohydrates (RDC) according to different dietary levels of cottonseed hulls (CA)

\begin{tabular}{|c|c|c|c|c|c|c|c|}
\hline \multirow[t]{2}{*}{$\begin{array}{l}\text { Item } \\
\text { Item }\end{array}$} & \multicolumn{4}{|c|}{$\begin{array}{l}\text { Nível de casca de algodão (\%) } \\
\text { Cottonseed hulls level (\%) }\end{array}$} & \multirow[b]{2}{*}{ Equação } & \multirow[b]{2}{*}{ CV $(\%)$} & \multirow[b]{2}{*}{$r^{2}$} \\
\hline & 0 & 10 & 20 & 30 & & & \\
\hline \multicolumn{8}{|c|}{$\begin{array}{l}\text { Consumo }(\mathrm{kg} / \mathrm{dia}) \\
\text { Intake }(\mathrm{kg} / \text { day })\end{array}$} \\
\hline $\operatorname{MS}(D M)$ & 6,63 & 7,44 & 7,62 & 8,26 & $\hat{\mathrm{Y}}=6,7472+0,0498 * \mathrm{CA}$ & 11,04 & 0,21 \\
\hline $\mathrm{MO}(O M)$ & 6,19 & 7,00 & 7,21 & 7,87 & $\hat{\mathrm{Y}}=6,3012+0,0516^{*} \mathrm{CA}$ & 10,95 & 0,25 \\
\hline $\mathrm{PB}(C P)$ & 0,98 & 1,03 & 1,11 & 1,20 & $\hat{\mathrm{Y}}=0,9666+0,0076^{*} \mathrm{CA}$ & 10,74 & 0,23 \\
\hline $\mathrm{EE}$ & 0,17 & 0,20 & 0,22 & 0,24 & $\hat{\mathrm{Y}}=0,1768+0,0022 * * \mathrm{CA}$ & 10,26 & 0,41 \\
\hline FDNcp (NDFap) & 2,87 & 3,33 & 3,43 & 3,76 & $\hat{\mathrm{Y}}=2,946+0,0271 * \mathrm{CA}$ & 11,90 & 0,27 \\
\hline CNFcp (NFCap) & 2,27 & 2,69 & 2,74 & 2,97 & $\hat{\mathrm{Y}}=2,3477+0,0212 * \mathrm{CA}$ & 16,54 & 0,27 \\
\hline $\operatorname{NDT}(T D N)$ & 3,62 & 4,38 & 4,56 & 4,88 & $\hat{\mathrm{Y}}=3,7729+0,0395^{*} \mathrm{CA}$ & 17,30 & 0,30 \\
\hline MOdr (RDOM) & 2,27 & 2,74 & 3,12 & 3,67 & $\hat{\mathrm{Y}}=2,2651+0,0457 * * \mathrm{CA}$ & 26,93 & 0,35 \\
\hline $\mathrm{CHOdr}(R D C)$ & 1,80 & 2,25 & 2,63 & 3,03 & $\hat{\mathrm{Y}}=3,4956+0,0395 * * \mathrm{CA}$ & 24,68 & 0,44 \\
\hline \multicolumn{8}{|c|}{$\begin{array}{l}\text { Consumo }(\% \mathrm{PV}) \\
\text { Intake }(\% B W)\end{array}$} \\
\hline $\operatorname{MS}(D M)$ & 2,46 & 2,89 & 2,97 & 3,14 & $\hat{\mathrm{Y}}=2,566+0,020439 * \mathrm{CA}$ & 8,59 & 0,43 \\
\hline $\mathrm{FDN}(N D F)$ & 1,06 & 1,30 & 1,34 & 1,43 & $\hat{\mathrm{Y}}=1,1216+0,010974 * * \mathrm{CA}$ & 9,00 & 0,41 \\
\hline
\end{tabular}

* Significativo a $5 \%$ de probabilidade, pelo teste $\mathrm{F}$.

** Significativo a $1 \%$ de probabilidade, pelo teste $\mathrm{F}$.

* Significant at $5 \%$ of probability ( $F$ test).

* Significant at $1 \%$ of probability ( $F$ test).

encontrados na literatura sugerem que o uso de casca de algodão na dieta tem proporcionado consumos superiores, sem, no entanto, aumentar a produtividade animal.

$\mathrm{Na}$ Tabela 5 são apresentadas as médias, equações de regressão e coeficientes de variação obtidos para os coeficientes de digestibilidade aparente total dos nutrientes, bem como os teores de nutrientes digestíveis totais, para os diferentes níveis de casca de algodão nas rações. Observa-se que não houve influência dos níveis de casca de algodão sobre as digestibilidades e, conseqüentemente, não houve efeito sobre o teor de NDT das dietas, que foi, em média, de $59,53 \%$. Embora o consumo de MS, e possivelmente a taxa de escape da digesta ruminal, tenham aumentado nas dietas com maiores teores de casca de algodão, não foram identificadas diferenças entre os tratamentos em nenhum dos coeficientes de digestibilidade avaliados.

Moore et al. (1990) reportaram decréscimo na digestibilidade da MS, quando a casca de algodão substituiu o feno de alfafa ou a palhada de trigo, mas o teor de FDN da dieta contendo casca $(30,3 \%)$ foi superior ao das dietas com feno de alfafa ou palhada de trigo (22,9 e 24,2\%, respectivamente). Vale ressaltar que, no presente experimento, o teor de FDN das dietas foi similar (Tabela 3), não sendo encontrada diferença na digestibilidade da MS. Akinyode et al. (1999), substituindo $40 \%$ da silagem de sorgo por casca de algodão também relataram decréscimo na digestibilidade da MS e MO e aparente aumento na taxa de passagem ruminal.

$\mathrm{O}$ teor de NDT da casca de algodão estimado $(55,52 \%)$ foi superior aos valores de $44 \%$ encontrado por Hale et al. (1969) e de 47,9\% estimado a partir das equações propostas pelo NRC (2001).

$\mathrm{Na}$ Tabela 6 são apresentadas as médias, equações de regressão e coeficientes de variação obtidas para os coeficientes de digestibilidade aparente ruminal e intestinal dos nutrientes, para os diferentes níveis de casca de algodão nas dietas. As digestões ruminais e intestinais de todos nutrientes avaliados não diferiram estatisticamente. A digestão de MS, MO, FDNcp e 
Tabela 5 - Médias, equações de regressão (equações), coeficientes de variação (CV) e probabilidades (P), obtidos para os coeficientes de digestibilidade aparente total da matéria seca (MS), matéria orgânica (MO), proteína bruta (PB), extrato etéreo (EE), fibra em detergente neutro corrigida para cinzas e proteína (FDNcp), carboidratos não-fibrosos corrigidos (CNFcp) e teores de nutrientes digestíveis totais (NDT), em função dos níveis de casca de algodão nas rações, em porcentagem

Table 5 - Means, regression equation (equations), coefficients of variation (CV) and probabilities ( $P$ ) of total apparent digestibilities of dry matter (DM), organic matter (OM), crude protein (CP), ether extract (EE), corrected neutral detergent fiber (NDFap), corrected nonfiber carbohydrates (NFCap), and total digestible nutrients (TDN) according to different dietary levels of cottonseed hulls

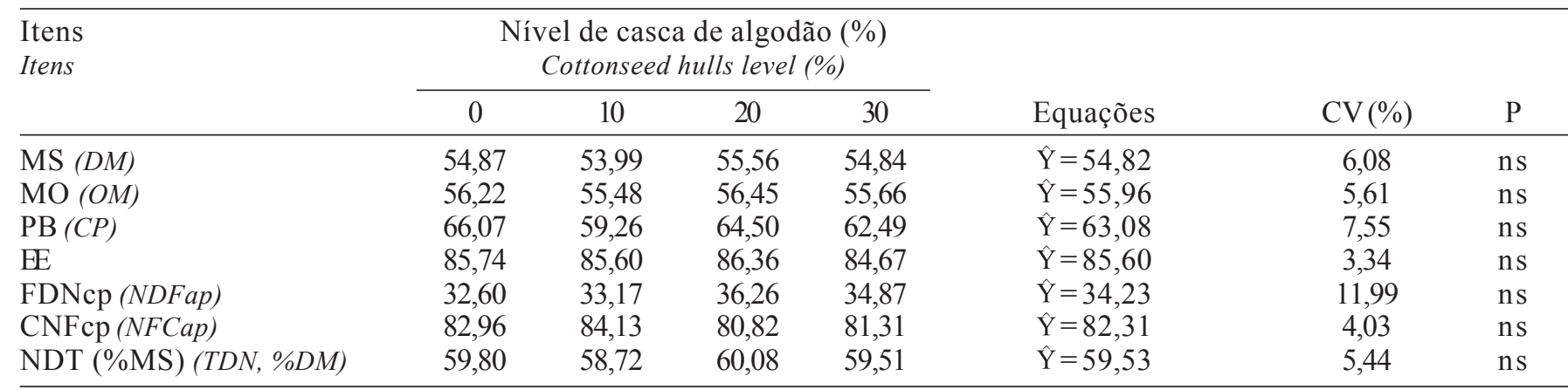

ns - não-significativo a $5 \%$ de probabilidade, pelo teste de Newman Keuls.

ns - not significant at $5 \%$ of probability (Newman Keuls test).

Tabela 6 - Médias, equações de regressão (equações), coeficientes de variação (CV) e probabilidades (P) obtidos para os coeficientes de digestibilidade ruminal e intestinal da matéria seca (MS), matéria orgânica (MO), proteína bruta $(P B)$, extrato etéreo (EE), fibra em detergente neutro corrigida para cinzas e proteína (FDNcp) e carboidratos não-fibrosos corrigidos (CNFcp), em função dos níveis de casca de algodão nas dietas

Table 6 - Means, regression equation (equations), coefficients of variation (CV) and probabilities $(P)$ of ruminal and intestinal digestibilities of dry matter (DM), organic matter (OM), crude protein (CP), ether extract (EE), corrected neutral detergent fiber (NDFap), and corrected nonfiber carbohydrates (NFCap) according to different dietary levels of cottonseed hulls

Itens Nível de casca de algodão (\%)

Itens Cottonseed hulls level (\%)

$\begin{array}{llll}0 & 10 & 20 & 30\end{array}$

Equações

CV $(\%)$

$\mathrm{P}$

Digestibilidade ruminal

Ruminal digestibility

\begin{tabular}{|c|c|c|c|c|c|c|c|}
\hline $\mathrm{MS}^{1}(D M)$ & 54,44 & 54,23 & 62,49 & 72,88 & $\hat{\mathrm{Y}}=61,01$ & 28,74 & $\mathrm{~ns}$ \\
\hline $\mathrm{MO}^{1}(O M)$ & 71,34 & 68,86 & 76,93 & 84,19 & $\hat{Y}=75,33$ & 18,85 & $\mathrm{~ns}$ \\
\hline $\mathrm{PB}^{2}(C P)$ & 37,20 & 29,21 & 28,63 & 35,89 & $\hat{\mathrm{Y}}=32,73$ & 46,05 & $\mathrm{~ns}$ \\
\hline $\mathrm{EE}^{2}$ & $-12,71$ & $-0,66$ & 7,04 & $-7,75$ & $\hat{Y}=-3,52$ & 373,51 & $\mathrm{~ns}$ \\
\hline $\mathrm{FDNcp}^{1}$ (NDFap) & 86,33 & 83,02 & 94,33 & 92,52 & $\hat{\mathrm{Y}}=89,05$ & 21,45 & $\mathrm{~ns}$ \\
\hline $\mathrm{CNFcp}^{1}$ (NFCap) $^{-1}$ & 72,11 & 68,89 & 77,94 & 88,90 & $\hat{\mathrm{Y}}=76,96$ & 27,56 & $\mathrm{~ns}$ \\
\hline
\end{tabular}

Digestibilidade intestinal

Intestinal digestibility

\begin{tabular}{|c|c|c|c|c|c|c|c|}
\hline $\mathrm{MS}^{1}(D M)$ & 45,56 & 45,76 & 37,51 & 27,12 & $\hat{\mathrm{Y}}=38,99$ & 44,96 & $\mathrm{~ns}$ \\
\hline $\mathrm{EE}^{2}$ & 89,36 & 79,05 & 75,99 & 91,94 & $\hat{Y}=84,08$ & 6,70 & $\mathrm{~ns}$ \\
\hline $\mathrm{CNFcp}^{1}$ (NFCap) & 27,89 & 31,11 & 22,06 & 11,10 & $\hat{\mathrm{Y}}=23,04$ & 515,31 & $\mathrm{~ns}$ \\
\hline
\end{tabular}

\footnotetext{
${ }^{1}$ Expresso em \% do total digerido.

${ }^{2}$ Expresso em \% da quantidade que chegou a cada local.

ns - não-significativo a $5 \%$ de probabilidade, pelo teste de Newman Keuls.

${ }^{1}$ Expressed as \% of total digested.

2 Expressed as \% of the amounts that flowed to each site.

$n s-$ not significant at $5 \%$ of probability (Newman Keuls test).
} 
CNFcp ocorreu em maior extensão no rúmen. A digestibilidade da MS ruminal apresentou média de $61,01 \%$, sendo verificada diferença numérica de $34 \%$ entre os tratamentos sem casca e com $30 \%$ de casca de algodão. Estudando os locais de digestão, Valadares Filho (1985) encontrou que aproximadamente $58 \%$ da fração digestível da matéria seca é degradada no rúmen. Kropp et al. (1977) reportaram digestibilidade ruminal da MO média de $62 \%$ em dietas contendo em torno de $75 \%$ de casca de algodão. A digestibilidade ruminal da $\mathrm{PB}$, expressa em \% da proteína ingerida, apresentou média de $32,73 \%$, indicando absorção de $\mathrm{NH}_{3}$ pelo epitélio ruminal e perda de proteína dietética. A digestibilidade ruminal do EE apresentou coeficientes negativos, indicando síntese de lipídeos microbianos.
As digestões intestinais dos nutrientes também não foram afetadas pela inclusão da casca de algodão na dieta. Apenas a digestão lipídica ocorreu em maior extensão nos intestinos, visto que no ambiente ruminal não há presença de microrganismos capazes de utilizar lipídeos como fonte de energia.

$\mathrm{Na}$ Tabela 7 encontram-se as estimativas da fração solúvel (a), da fração potencialmente degradável (b) e da taxa de solubilização da fração b $(\mathrm{Kd})$ das equações ajustadas para a degradabilidade da MS e PB e a estimativa da fração potencialmente degradável (b), da fração indigestível (i), do tempo de latência ou lag time (L), a taxa de solubilização da fração b das equações ajustadas para a degradabilidade da FDN e a degradação efetiva da MS, PB e FDN. A

Tabela 7 - Estimativa dos coeficientes a (\%), b (\%), Kd (\%/hora) das equações ajustadas para a degradabilidade da matéria seca (MS) e proteína bruta (PB), estimativa dos coeficientes b (\%), Kd (\%/hora), i (\%) e L (horas) das equações ajustadas para a degradabilidade da FDN, degradação ruminal efetiva (DE, em \%) e respectivos coeficientes de determinação $\left(\mathrm{R}^{2}\right)$ para os alimentos utilizados

Table 7 - Estimation of coefficients a (\%), b (\%), Kd (\%/hour) of the adjusted equations for DM and CP degradabilities, estimation of the coefficients $b(\%), K d$ (\%/hour), $i(\%)$ and $L$ (hours) of the adjusted equations for NDF degradability, ruminal effective degradability $(E D, \%)$ and the respective coefficients of determination $\left(R^{2}\right)$ of the feeds

\begin{tabular}{lcc}
\hline Alimento & Coeficiente & $\mathrm{R}^{2}$ \\
Feed & Coefficient & ED \\
\hline
\end{tabular}

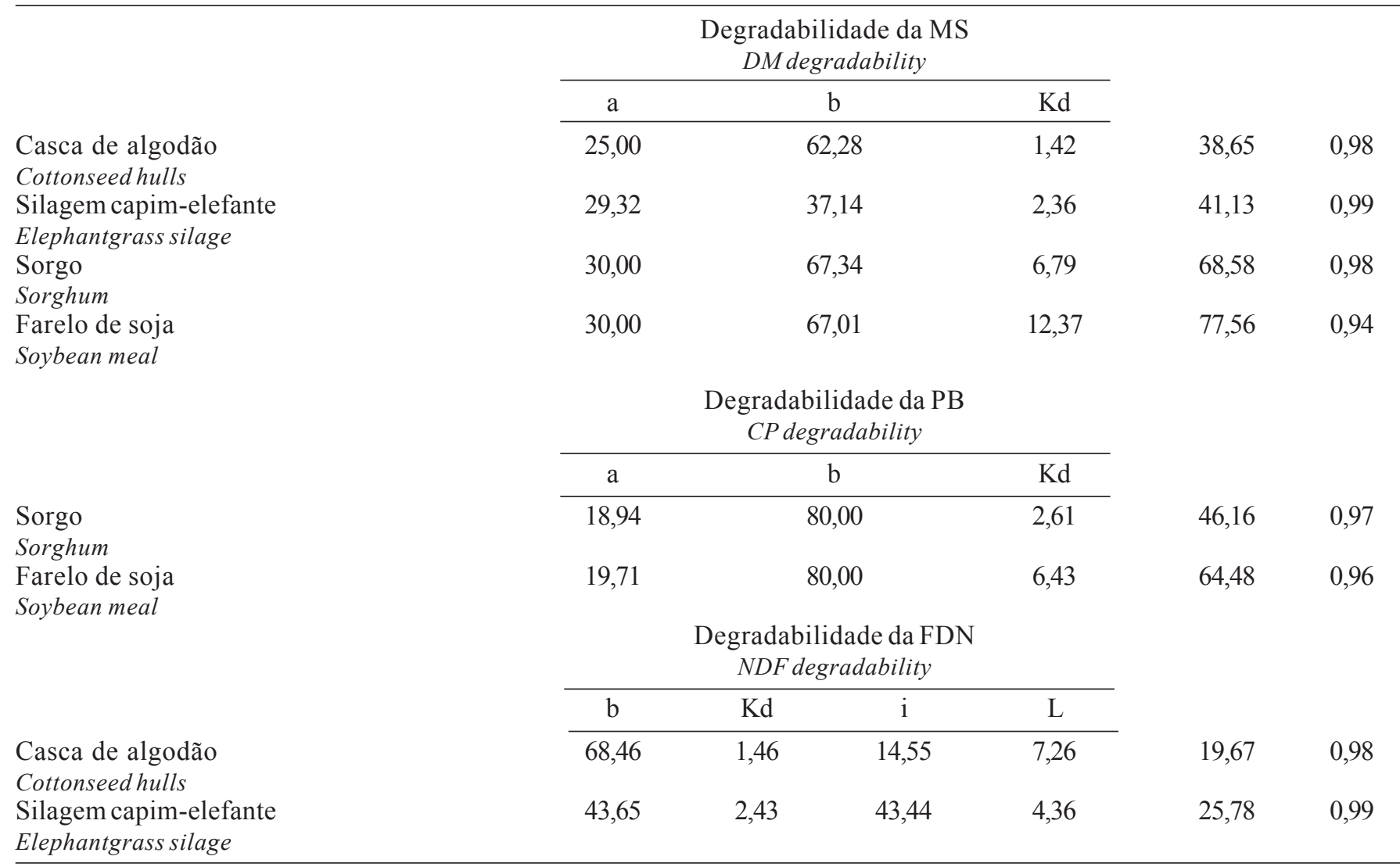


taxa de passagem (média dos quatro tratamentos) estimada pelas equações propostas pelo NRC (2001) foi de $5,06 \% / \mathrm{h}$, e esse valor foi utilizado para o cálculo das degradações efetivas.

Os resultados encontrados aproximam-se daqueles relatados em Valadares Filho et al. (2002b), que reportaram médias das frações a e b e do Kd da MS de 32,$03 ; 65,67$ e $5 \%$ para o sorgo e $29,02,67,49$ e $8,95 \%$ para o farelo de soja, respectivamente. Nesta mesma publicação, as médias das frações a e b e do Kd da PB foram de 29,13; 60,8 e 5\% para o sorgo e 18,$21 ; 78,59$ e $9,9 \%$ para o farelo de soja.

Observa-se que a casca de algodão apresentou menores taxas de degradação tanto da MS quanto da FDN em relação aos demais ingredientes. Resultados semelhantes foram reportados por Moore et al. (1990), em que a taxa de degradação da MS da fração b foi de 5,6 e 3,3\%/ h para o feno de alfafa e a palhada de trigo e de $1,9 \% / \mathrm{h}$ para a casca de algodão, valor próximo ao encontrado neste trabalho de $1,42 \% / \mathrm{h}$ para o mesmo alimento. Hsu et al. (1987) encontraram taxa de desaparecimento da MS de $0,8 \% /$ h para casca de algodão. Entretanto neste estudo o período de incubação foi de 3 a 36 horas. Torrent et al. (1994), avaliando a digestibilidade da fibra de subprodutos reportaram menores taxas de desaparecimento, digestibilidade ruminal e total da FDN da casca de algodão em relação à polpa de beterraba, grão de cervejaria e feno de alfafa, encontrando taxa de desaparecimento da fração potencialmente degradável da FDN de 3,5\%/h e tempo de latência (lag time) de 2,7 horas para a casca de algodão, resultado discordante do observado no presente trabalho de 1,46\%/h e 7,26 horas, respectivamente. Embora lentamente degradável, a casca de algodão, em relação à silagem de capim-elefante, apresentou maior porcentagem da fração potencialmente degradável da MS (62,28 vs $37,14 \%)$ e da FDN $(68,46$ vs $43,65 \%)$ e menor teor de resíduo indigestível. Em contrapartida, as DE da MS e da FDN da silagem de capim-elefante, para a taxa de passagem estimada de $5,06 \% / \mathrm{h}$, foram superiores às da casca de algodão. Garleb et al. (1991) sugeriram que os elevados teores de celulose cristalina e lignina da casca de algodão são responsáveis pelo lento desaparecimento da FDN em ensaios in situ e in vivo.

\section{Conclusões}

A casca de algodão mostrou-se um bom volumoso alternativo, podendo ser fornecida até o nível de $30 \%$ na MS total, pois favoreceu o consumo dos nutrientes sem afetar a digestibilidade dos mesmos.

\section{Literatura Citada}

AKINYODE, A.; HALL, M.B.; STAPLES, C.R. et al. Effect of cottonseed hulls on feed intake and fecal flow in dairy cows. Journal of Dairy Science, v.82, (Supplement. 1), p.41, 1999.

ALLEN, M.S. Physical constaints on voluntary intake of forages by ruminants. Journal of Animal Science, v.74, p.30633075, 1996.

BARTLE, S.J.; PRESTON, R.L.; MILLER, M.F. Dietary energy source and density: effects if roughage source, roughage equivalent, tallow level and steer type on feedlot performance and carcass characteristics. Journal of Animal Science, v.72, p.1943-1953, 1994.

CHURCH, D.C. The ruminant animal - Digestive physiology and nutrition. Illinois: Waveland Press, 1993. 564p.

COCHRAN, R.C.; ADAMS, D.C.; WALLACE, J.D. et al. Predicting digestibility diets with internal markers: evaluation of four potential markers. Journal of Animal Science, v.63, p.1476-1483, 1986.

DEFOOR, P.J.; GALYEAN, M.L.; SALYER, G.B. et al. Effects of roughage source and concentration on intake and performance by finishing heifers. Journal of Animal Science, V.80, p.1395-1404, 2002

GARLEB, K.A.; BOURQUIN, L.D.; HSU, J.T. et al. Isolation and chemical analyses of nonfermented fiber fractions of oat hulls and cottonseed hulls. Journal of Animal Science, v.69, p.1255-1271, 1991.

HALE, W.H.; LAMBETH, C.; THEURER, B. et al. Digestibility and utilization of cottonseed hulls by cattle. Journal of Animal Science, v.29, n.5, p.773-776, 1969.

HALL, M.B.; AKINYODE, A. Cottonseed hulls: working with a novel fiber source. In: ANNUAL FLORIDA RUMINANT NUTRITION SYMPOSIUM, 11., 2000, Gainesville. Proceedings... Gainesville, 2000. p.179-186.

HALL, M.B. Calculation of non-structural carbohydrate content of feeds that contain non-protein nitrogen. University of Florida, 2000. p.A-25 (Bulletin 339, April- 2000).

HSU, J.T.; FAULKNER, D.B.; GARLEB, K.A. et al. Evaluation of corn fiber, cottonseed hulls, oat hulls and soybean hulls as roughage sources for ruminants. Journal of Animal Science, V.65, p.244-255, 1987.

KROPP, J.R.; JOHNSON, R.R.; MALES, J.R. et al. Microbial protein synthesis with low quality roughage rations: Level and source of nitrogen. Journal of Animal Science, v.46, p.844-854, 1977.

LEÃO, M.I.; COELHO DA SILVA, J.F. Técnicas de fistulação de abomaso em bezerros. In: CONGRESSO BRASILEIRO DE ZOOTECNIA, 1. REUNIÃO ANUAL DA SOCIEDADE BRASILEIRA DE ZOOTECNIA, 17., 1980, Fortaleza. Anais... Fortaleza: Sociedade Brasileira de Zootecnia, 1980. p.37.

LEÃO, M.I.; VALADARES FILHO, S.C.; AZEVEDO, J.A.G. et al. Técnica de coleta de digesta omasal para estudos de digestão parcial em bovinos. In: REUNIÃO ANUAL DA SOCIEDADE BRASILEIRA DE ZOOTECNIA, 39., 2002, Recife. Anais... Recife: 2002. CD-ROM. Nutrição de Ruminantes.

MAGALHÃES, K.A.; VALADARES FILHO, S.C.; CHIZZOTTI, M.L. et al. Consumo e desempenho de novilhos de origem leiteira em confinamento alimentados com diferentes níveis de casca de algodão. In: REUNIÃO ANUAL DA SOCIEDADE BRASILEIRA DE ZOOTECNIA, 40., Santa Maria. Anais... Santa Maria: Sociedade Brasileira de Zootecnia, 2003. CD-ROM. Nutrição de Ruminantes. 
MERTENS, D.R.; LOFTEN, J.R. The effect of starch on forage fiber digestion in vitro. Journal of Dairy Science, v.63, p.1437-1446, 1980.

MORALES, J.L.; Van HORN, H.H.; MOORE, J.E. Dietary interaction of cane molasses with source of roughage: intake and lactation effects. Journal of Dairy Science, v.72, p.2331-2338, 1989 .

MOORE, J.A.; POORE, M.H.; SWINGLE, R.S. Influence of roughage source on kinetics of digestion and passage, and on calculated extents of ruminal digestion in beef steers fed $65 \%$ concentrate diets. Journal of Animal Science, v.68, p.3412-3420, 1990.

NATIONAL RESEARCH COUNCIL - NRC. Nutrient requirements of beef cattle. 7.ed. Washington, D.C.: National Academy, 1996. 242p.

NATIONAL RESEARCH COUNCIL - NRC. Nutrient requeriments of dairy cattle. 7.ed. Washington, D.C.: National Academic Press, 2001. 381p.

ORSKOV, E.R.; McDONALD, I. The estimation of protein degradability in the rumen from incubation measurements weighted according to rate of passage. Journal of Agricultural Science, v.92, p.499-503, 1979.

RENNÓ, L.N.; VALADARES FILHO, S.C.; PAULINO, M.F. et al. Indicadores interno ou externo e efeito da contaminação da fibra em detergente neutro sobre a digestibilidade aparente total em novilhos. In: REUNIÃO ANUAL DA SOCIEDADE BRASILEIRA DE ZOOTECNIA, 39., 2002, Recife. Anais... Recife: 2002. CD-ROM. Nutrição de ruminantes.

SILVA, D.J.; QUEIROZ, A.C. Análise de alimentos (Métodos químicos e biológicos). 3.ed. Viçosa, MG: Universidade Federal de Viçosa, 2002. 235p.
TORRENT, J.; JOHNSON, D.E.; KUJAWA, M.A. Co-product fiber digestibility: kinetic and in vivo assessment. Journal of Animal Science, v.72, p.790-795, 1994.

UNIVERSIDADE FEDERAL DE VIÇOSA - UFV. Departamento de Engenharia Agrícola. Estação Meteorológica. Viçosa: 2002. n.p.

UNIVERSIDADE FEDERAL DE VIÇOSA - UFV. SAEG Sistema de análises estatísticas e genéticas. Versão 8.0 Viçosa, MG: 1998. 150p. (Manual do usuário).

VALADARES FILHO, S.C. Digestão total e parcial da matéria seca e carboidratos em bovinos e bubalinos. Viçosa, MG: Universidade Federal de Viçosa, 1985. 147p. Tese (Doutorado em Zootecnia) - Universidade Federal de Viçosa, 1985.

VALADARES FILHO, S.C.; PAULINO, P.V.R.; MAGALHÃES, K.A. et al. Modelos nutricionais alternativos para otimização de renda na produção de bovinos de corte. In: SIMCORTE SIMPÓSIO DE PRODUÇÃO DE GADO DE CORTE, 3. 2002, Viçosa, MG. Anais... Viçosa, MG: Universidade Federal de Viçosa, 2002a. p.197-254.

VALADARES FILHO, S.C.; ROCHA JR., V.R.; CAPPELLE, E.R. Tabelas brasileiras de composição de alimentos para bovinos. CQBAL 2.0. Viçosa, MG: Universidade Federal de Viçosa/Suprema Gráfica Ltda, 2002b. 297p.

Recebido em: 20/09/04

Aceito em: 08/06/05 